\title{
Bidirectional Human-Swine Transmission of Seasonal Influenza A(H1N1)pdm09 Virus in Pig Herd, France, 2018
}

\author{
Amélie Chastagner, ${ }^{1}$ Vincent Enouf, ${ }^{1}$ \\ David Peroz, Séverine Hervé, Pierrick Lucas, \\ Stéphane Quéguiner, Stéphane Gorin, \\ Véronique Beven, Sylvie Behillil, \\ Philippe Leneveu, Emmanuel Garin, \\ Yannick Blanchard, Sylvie van der Werf, \\ Gaëlle Simon
}

In 2018, a veterinarian became sick shortly after swabbing sows exhibiting respiratory syndrome on a farm in France. Epidemiologic data and genetic analyses revealed consecutive human-to-swine and swine-to-human influenza $A(H 1 N 1) p d m 09$ virus transmission, which occurred despite some biosecurity measures. Providing pig industry workers the annual influenza vaccine might reduce transmission risk.

$I^{n}$ n April 2009, a novel influenza A virus (IAV) emerged in humans in North America and spread in the human population worldwide, leading to the first pandemic of the 21 st century (1). This virus, influenza A(H1N1)pdm09 ( $\mathrm{pH} 1 \mathrm{~N} 1)$, suspected to have resulted from reassortment among IAVs of swine origin, was rapidly transmitted to pig populations. This virus became seasonal in humans (2) and enzootic in several pig populations, including those in Europe (3). Moreover, phylogenetic analyses suggest de novo human-to-swine $\mathrm{pH} 1 \mathrm{~N} 1$ transmission occurs during seasonal epidemics (4-6). In this study, we provide evidence of bidirectional transmission of $\mathrm{pH} 1 \mathrm{~N} 1$ between humans and pigs in a herd located in France.

\section{The Study}

In January of the 2017-18 seasonal influenza epidemic in humans, a farmer reported to a veterinarian an acute

Author affiliations: French Agency for Food, Environmental and Occupational Health, and Safety, Ploufragan, France

(A. Chastagner, S. Hervé, P. Lucas, S. Quéguiner, S. Gorin, V. Beven, Y. Blanchard, G. Simon); Institut Pasteur, Paris, France (V. Enouf, S. Behillil, S. van der Werf); Atlantic Vétérinaires,

Ancenis, France (D. Peroz); CEVA Santé Animale SA, Libourne, France (P. Leneveu); Coop de France, Paris (E. Garin);

Plateforme Epidémiosurveillance Santé Animale, Lyon, France

(E. Garin)

DOI: https://doi.org/10.3201/eid2510.190068 respiratory outbreak in the pregnant sows of his farrow-towean herd. The animals of this herd $(\approx 1,000$ sows $)$ were not vaccinated against swine IAVs. The sows exhibited an influenza-like illness (ILI) of usual intensity (i.e., hyperthermia, apathy, dyspnea, sneezing, and coughing that did not last for $>2-3$ days for individual animals). On January 17 , the veterinarian and a technician handled the animals and, using nasal swabs (MW950Sent2mL Virocult; Kitvia, https://www.kitvia.com), collected samples from 3 sows (sample nos. 180028-1, 180028-2, 180028-3), as specified by the National Network for Surveillance of Type A Influenza Virus in Swine (7). The veterinarian (72 hours later) and technician (48 hours later), both not vaccinated against seasonal influenza, had ILI symptoms (i.e., tiredness, runny nose, chills). Neither reported close contact with humans with ILI before their symptom onset. On days 5 and 6 after handling the pigs, the veterinarian self-collected nasal swab samples (sample nos. 180130-1 and 180130-2).

The veterinarian submitted the nasal swab samples from sows to a local veterinary laboratory to determine the diagnosis. This laboratory used quantitative reverse transcription PCR of the influenza matrix gene for IAV detection (8). All 3 samples were positive for IAV and were sent to the National Reference Laboratory (Ploufragan, France) for subtyping. Here, we typed the isolates' hemagglutinin (HA) and neuraminidase genes by using quantitative reverse transcription PCRs specific to swine IAV lineages known to circulate in the pig populations in France (8). The HA and neuraminidase genes we identified were exclusively those of $\mathrm{pH} 1 \mathrm{~N} 1$. We propagated sample no. 180028-2 through Madin-Darby canine kidney cells (1 passage) to obtain isolate $\mathrm{A} / \mathrm{sw} /$ France/53-180028/2018. We sequenced the whole genome of this virus using an Ion Proton Sequencer (Thermo Fisher Scientific, https://www. thermofisher.com) at the Next-Generation Sequencing Platform of the French Agency for Food, Environmental and Occupational Health, and Safety (Ploufragan, France) (Appendix, https://wwwnc.cdc.gov/EID/article/25/10/190068-App1.pdf).

In parallel, we amplified the 8 virus genome segments from the 2 veterinarian self-collected nasal swabs and the 3 sow samples using universal primers (9) at the National

${ }^{1}$ These first authors contributed equally to this article. 
Reference Center for Respiratory Viruses (Paris, France). Then, we sequenced them on a NextSeq 500 System (Illumina Inc., https://www.illumina.com) at the Mutualized Platform for Microbiology (Paris, France) (Appendix). After cleaning reads, we excluded from analysis data from sample no. 180028-1 because of its low number of residual reads.

In all, we obtained 5 sets of 8 genomic segment sequences (BioProject no. PRJNA507096): 1 from A/sw/ France/53-180028/2018, 2 from pigs (sample nos. 1800282 and 180028-3), and 2 from a human (sample nos. 1801301 and 180130-2). We found only 3 nucleotide ambiguities supported by $>30 \%$ of reads: an A-G $(45.3 \%)$ mixture at position 1,667 in the polymerase basic 2 gene of sample no. $180028-2$ and a T-C (49.3\%) mixture at position 862 and C-A $(34.9 \%)$ mixture at position 867 in the HA gene of sample no. 180130-1 (nucleotide numbering starting from first position of coding sequence for all). Excluding these ambiguities, the 5 virus genomes were $100 \%$ identical, regardless of source or sequencing pipeline. We compared these virus sequences with those of other $\mathrm{pH} 1 \mathrm{~N} 1$ strains available in the GISAID database (https://www.gisaid.org) using the integrated BLAST program; the highest similarities (up to $99.94 \%$ identity) were found with a $\mathrm{pH} 1 \mathrm{~N} 1$ isolate identified in a population in France during the 2017-18 winter influenza season (Table). We performed maximum-likelihood phylogenetic analyses that included pH1N1 viruses isolated from pigs and humans in France during 2009-2018. Whatever the genomic segment used, be that encoding HA (Figure) or others (data not shown), the isolates from our case study were more closely related to seasonal influenza isolates than isolates from the swinespecific lineage identified in France during 2015-2016 (6), confirming our BLAST results.

The timing of events and results of analyses led to multiple hypotheses: that de novo human-to-swine pH1N1 virus transmission would have been responsible for the first infection in this herd, that swine-to-swine transmission within the herd would have then been responsible for additional animal infections, and that subsequent swine-tohuman transmission would have been responsible for the infection in the veterinarian and probably also the one in the technician. Because gilts (i.e., $<1$-year-old female pigs) were not introduced into the herd during the weeks before the acute respiratory outbreak, the virus was most probably transmitted to sows by an infected person who entered the farm, probably an employee who, according to the farmer, displayed an ILI a few days before he spotted the first clinical signs in sows. This employee took a shower before entering the breeding area and put on dedicated clothes but did not wear a protective mask or gloves. Likewise, swineto-human transmission was probably facilitated by the veterinarian and technician not wearing personal protective equipment when handling the sick sows. In either of these situations, transmission probably resulted from contact with respiratory secretions or inhalation of aerosols generated by shedding humans or animals or by contact with contaminated fomites (10).

Serologic investigations have previously suggested that occupational exposure to pigs is a risk factor for human infections (11), but events of bidirectional pH1N1 interspecies transmission have been rarely demonstrated. This report confirms pH1N1 virus can easily be transmitted between pigs and humans. Other swine IAVs were inherited completely or partially from human IAVs, but $\mathrm{pH} 1 \mathrm{~N} 1$ virus was suspected to be introduced to swine more frequently than other strains, potentially because the virus's origin was probably swine (5). After such reverse zoonotic events, the strain might undergo evolutionary adaptation, as revealed by the previously identified swine-specific genogroup (6); in cases of further antigenic divergence, these strains could constitute novel threats for humans lacking cross-immunity. Moreover, because of co-infections with other swine IAVs, numerous reassortants bearing $\geq 1 \mathrm{pH} 1 \mathrm{~N} 1$ genomic segment have been described worldwide, and some of these strains have become enzootic in pig populations $(3,5)$. Such reassortants could also be an increased risk to the public health, as illustrated by many swine-to-human transmission events of swine IAVs containing the pH1N1 matrix gene during exhibition fairs in the United States (12). These transmissions have strongly increased the number of zoonotic infections reported since the last pandemic; only a few cases were reported before $2009(13,14)$.

\section{Conclusions}

The emergence of novel IAVs that threaten both human and swine health can be facilitated by the virus crossing species

Table. Influenza A(H1N1)pdm09 strains closest related to A/sw/France/53-180028/2018 isolated from a sow in France, 2018*

\begin{tabular}{|c|c|c|c|c|c|c|c|c|c|c|}
\hline \multirow[b]{3}{*}{ Influenza A(H1N1)pdm09 strain† } & \multirow{3}{*}{$\begin{array}{c}\text { Collection } \\
\text { date }\end{array}$} & \multicolumn{9}{|c|}{ Percentage identity } \\
\hline & & \multicolumn{8}{|c|}{ Segment no. (gene) } & \multirow{2}{*}{$\begin{array}{c}\text { Whole } \\
\text { genome }\end{array}$} \\
\hline & & 1 (PB2) & 2 (PB1) & $3(\mathrm{PA})$ & $4(\mathrm{HA})$ & $5(\mathrm{NP})$ & 6 (NA) & $7(\mathrm{M})$ & 8 (NS) & \\
\hline A/Haute Normandie/1985/2017 & 2017 Dec 28 & 99.96 & 99.91 & 100.00 & 99.88 & 100.00 & 99.93 & 100.00 & 99.77 & 99.94 \\
\hline A/Dijon/181/2018 & 2017 Dec 31 & 99.96 & 99.91 & 99.95 & 99.82 & 100.00 & 99.86 & 100.00 & 99.88 & 99.94 \\
\hline A/Alsace/560/2018 & 2018 Jan 22 & 99.91 & 99.96 & 100.00 & 99.82 & 100.00 & 99.93 & 100.00 & 99.77 & 99.93 \\
\hline A/Paris/1767/2017 & 2017 Dec 15 & 99.96 & 99.96 & 99.95 & 99.76 & 100.00 & 100.00 & 99.90 & 99.77 & 99.92 \\
\hline
\end{tabular}




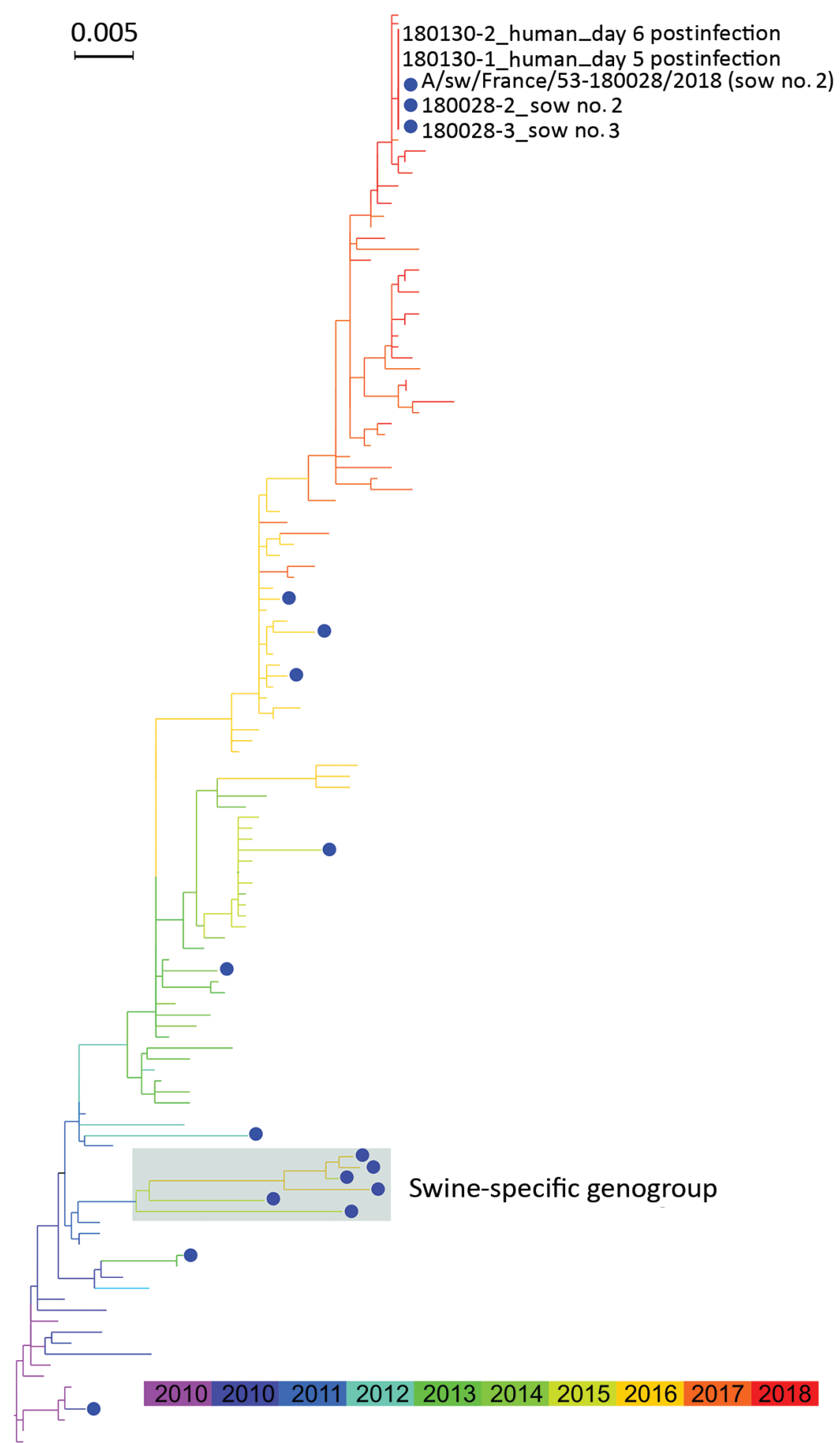

Figure. Maximum-likelihood phylogenetic tree of hemagglutinin segments from influenza $A(\mathrm{H} 1 \mathrm{~N} 1)$ pdm09 isolates from swine (blue dots) and humans, France, 2009-2018. Shaded box indicates swine-specific genogroup previously described by Chastagner et al. (6). barriers $(4,15)$. The concomitant $\mathrm{pH} 1 \mathrm{~N} 1$ virus infections we report emphasize the importance of implementing ad hoc biosecurity measures in pig farms to prevent interspecies virus transmission (10). Our evidence supports the One Health perspective of providing pig industry workers the annual seasonal influenza vaccination. This practice can minimize the risk for workers acquiring $\mathrm{pH} 1 \mathrm{~N} 1$ virus infections from pigs and for workers transmitting human IAVs to pigs.

\section{Acknowledgments}

The authors are indebted to all members from RÉSAVIP (Réseau National de Surveillance des Virus Influenza Chez le Porc), also known as the National Network for Surveillance of Type A Influenza Virus in Swine.

This work was partially funded by the European Union Horizon 2020 program 503 COMPARE (Collaborative Management Platform for detection and Analyses of [Re-]emerging and foodborne 
outbreaks in Europe; no. 643476) and by Santé Publique France for the coordinating center of the National Reference Center for Respiratory Viruses (including influenza) at Institut Pasteur.

\section{About the Author}

Dr. Chastagner is a molecular epidemiologist working in the Swine Virology Immunology Unit and National Reference Laboratory for Swine Influenza at Agence Nationale de Sécurité Sanitaire de l'Alimentation, de l'Environnement et du Travail, Ploufragan, France. Her main research interests are genetic and antigenic evolution of swine influenza viruses.

\section{References}

1. Smith GJ, Vijaykrishna D, Bahl J, Lycett SJ, Worobey M, Pybus OG, et al. Origins and evolutionary genomics of the 2009 swine-origin H1N1 influenza A epidemic. Nature. 2009;459: 1122-5. https://doi.org/10.1038/nature08182

2. Adlhoch C, Broberg E, Beauté J, Snacken R, Bancroft E, Zucs P, et al.; European Influenza Surveillance Network. Influenza season 2013/14 has started in Europe with influenza A(H1)pdm09 virus being the most prevalent subtype. Euro Surveill. 2014;19:20686. https://doi.org/10.2807/1560-7917.ES2014.19.4.20686

3. Simon G, Larsen LE, Dürrwald R, Foni E, Harder T, Van Reeth K, et al.; European Surveillance Network for Influenza in Pigs 3 Consortium. European Surveillance Network for Influenza in Pigs: surveillance programs, diagnostic tools and swine influenza virus subtypes identified in 14 European countries from 2010 to 2013. PLoS One. 2014;9:e115815. https://doi.org/10.1371/ journal.pone. 0115815

4. Nelson MI, Vincent AL. Reverse zoonosis of influenza to swine: new perspectives on the human-animal interface. Trends Microbiol. 2015;23:142-53. https://doi.org/10.1016/j.tim.2014.12.002

5. Watson SJ, Langat P, Reid SM, Lam TT, Cotten M, Kelly M, et al.; European Surveillance Network for Influenza in Pigs 3 Consortium. Molecular epidemiology and evolution of influenza viruses circulating within European swine between 2009 and 2013. J Virol. 2015;89:9920-31. https://doi.org/10.1128/JVI.00840-15

6. Chastagner A, Hervé S, Bonin E, Quéguiner S, Hirchaud E, Henritzi D, et al. Spatiotemporal distribution and evolution of the A/H1N1 2009 pandemic influenza virus in pigs in France from
2009 to 2017: identification of a potential swine-specific lineage. J Virol. 2018;92:e0988-18. https://doi.org/10.1128/JVI.00988-18

7. Garin E, Hervé S, Rose N, Locatelli C, Lecarpentier L, Ngwa-Mbot D, et al. National Network for Surveillance of Type A Influenza Virus in Swine (RÉSAVIP). Review of operations and surveillance results for 2016 [in French]. Bull Epidemiol Sante Anim Aliment. 2017;80:1-5.

8. Bonin E, Quéguiner S, Woudstra C, Gorin S, Barbier N, Harder TC, et al. Molecular subtyping of European swine influenza viruses and scaling to high-throughput analysis. Virol J. 2018;15:7. https://doi.org/10.1186/s12985-018-0920-z

9. Watson SJ, Welkers MR, Depledge DP, Coulter E, Breuer JM, de Jong MD, et al. Viral population analysis and minority-variant detection using short read next-generation sequencing. Philos Trans R Soc Lond B Biol Sci. 2013;368:20120205. https://doi.org/ 10.1098/rstb.2012.0205

10. Centers for Disease Control and Prevention. Flu can spread between pigs and people. 2018 Jul 5 [cited 2019 Jan 14]. https://www.cdc. gov/flu/pdf/swineflu/transmission-between-pigs-people.pdf

11. Fragaszy E, Ishola DA, Brown IH, Enstone J, Nguyen-Van-Tam JS, Simons R, et al.; Flu Watch Group; Combating Swine Influenza Consortium. Increased risk of A(H1N1)pdm09 influenza infection in UK pig industry workers compared to a general population cohort. Influenza Other Respir Viruses. 2016;10:291300. https://doi.org/10.1111/irv.12364

12. Bowman AS, Workman JD, Nolting JM, Nelson SW, Slemons RD. Exploration of risk factors contributing to the presence of influenza A virus in swine at agricultural fairs. Emerg Microbes Infect. 2014;3:1-5. https://doi.org/10.1038/emi.2014.5

13. Myers KP, Olsen CW, Gray GC. Cases of swine influenza in humans: a review of the literature. Clin Infect Dis. 2007;44:10848. https://doi.org/10.1086/512813

14. Kuntz-Simon G, Madec F. Genetic and antigenic evolution of swine influenza viruses in Europe and evaluation of their zoonotic potential. Zoonoses Public Health. 2009;56:310-25. https://doi.org/ 10.1111/j.1863-2378.2009.01236.x

15. Short KR, Richard M, Verhagen JH, van Riel D, Schrauwen EJA, van den Brand JMA, et al. One Health, multiple challenges: the inter-species transmission of influenza A virus. One Health. 2015;1:1-13. https://doi.org/10.1016/j.onehlt.2015.03.001

Address for correspondence: Gaëlle Simon, ANSES, Laboratoire de Ploufragan-Plouzané-Niort, Rue des Fusillés, Zoopôle Les Croix, BP 53, 22440 Ploufragan, France; email: gaelle.simon@anses.fr 